malleable blades were easily adjusted to accommodate variability in left atrial size and orientation of the pulmonary veins.

\section{Comment}

Development of new operative procedures has caused a resurgence in the surgical treatment of atrial fibrillation. Like the Cox maze procedure, these new operations generally include isolation of the pulmonary veins and excision of the left atrial appendage. Exposure of these structures, particularly in a large left atrium, is challenging.

A series of new atrial retractor blades (Kapp Surgical Inc, Cleveland, Ohio) provides exposure of the posterior left atrium and pulmonary vein orifices. These blades, which are malleable and universally adjustable, attach to a standard mitral valve retractor. This system provides excellent and consistent exposure of the posterior left atrium and pulmonary veins without the need for surgical assistance, facilitating operations for atrial fibrillation.

\title{
Clopidogrel before urgent coronary artery bypass graft
}

\author{
Michele Genoni, MD, ${ }^{a}$ Reza Tavakoli, MD, ${ }^{\text {a }}$ Christoph Hofer, MD, ${ }^{\mathrm{b}}$ Osmund Bertel, MD, ${ }^{\mathrm{c}}$ and Marko Turina, MD, ${ }^{\mathrm{a}}$ \\ Zurich, Switzerland
}

T he use of platelet aggregation agents, such as aspirin, glycoprotein IIb and IIIa inhibitors, and clopidogrel, has increased in recent years for patients with acute coronary syndromes, not least because of the results of the Clopidogrel in Unstable Angina to Prevent Recurrent Events study. ${ }^{1}$ In that study, clopidogrel significantly reduced the risk of cardiovascular death, myocardial infarction, strokes, and other related ischemic events in patients with acute coronary syndromes. Clopidogrel demonstrated benefits that were incremental to and independent of other therapies that the patients might have received, such as anticoagulants, angiotensin-converting enzyme inhibitors, $\beta$-blockers, and lipid-lowering agents. The study also confirmed the synergistic effect of the modes of action of clopidogrel and aspirin; clopidogrel inhibits adenosine 5'-diphosphateinduced platelet aggregation, whereas aspirin inhibits cyclooxygenase and reduces thromboxane $A_{2}$. The obvious inference from these findings is that all patients with an acute coronary syndrome should benefit from the favorable effects of clopidogrel, without exception and without delay, if possible in the prehospital period.

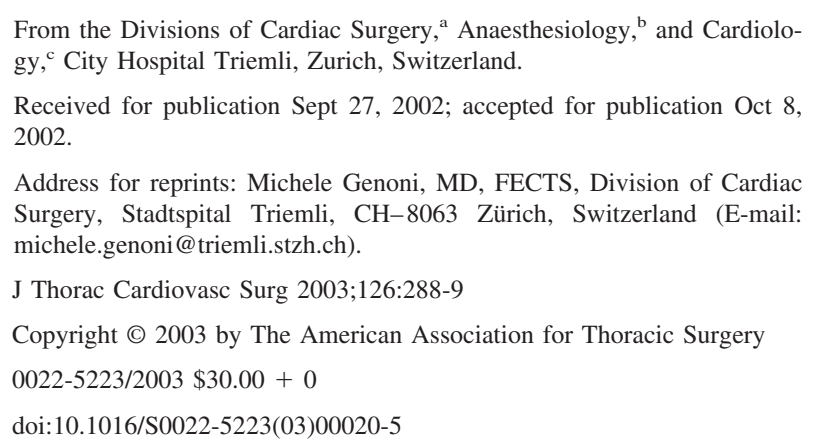

\section{References}

1. Cox JL, Ad N, Palazzo T, et al. Current status of the maze procedure of the treatment of atrial fibrillation. Semin Thorac Cardiovasc Surg. 2000;12:15-9.

2. Gillinov A.M., Smedira N.G., Cosgrove D.M. Microwave ablation of atrial fibrillation during mitral valve surgery. Ann Thorac Surg. 2002; 74:1259-61.

3. Gillinov A.M., Blackstone E.H., McCarthy P.M., Atrial fibrillation: current surgical options and their assessment. Ann Thorac Surg. 2002; 74:2210-7.

4. Cosgrove DM. A self-retaining retractor for mitral valve operations. J Thorac Cardiovasc Surg. 1986;92:305-6.
In this case, patients who have not had the opportunity to undergo coronary angiography with subsequent $\mathrm{PCI}$ and who are dependent on thrombolytic therapy, as well as those who require an urgent surgical revascularization, would also be treated with clopidogrel. This raises the question of indications and appropriateness of clopidogrel administration during the immediate preoperative course.

\section{Clinical Summary}

During a 12-month period (February 2001-January 2002), we performed 268 isolated coronary artery bypass grafts at our institution. For patients receiving clopidogrel medication, elective surgery was postponed at least 10 days after stopping clopidogrel. Of the 268 patients, however, 13 (4.8\%) (8 men, 5 women, mean age 68 years) required urgent operation after clopidogrel administration. All patients had an acute coronary syndrome and had received clopidogrel already before hospitalization (before coronary angiography). In 6 patients (group A), coronary artery bypass grafting was performed within 24 hours of hospitalization because of hemodynamic instability or critical coronary anatomy. These patients all received an intra-aortic balloon pump, a $\beta$-blocker, aspirin, and heparin. The remaining patients (group B) were operated after at least 7 days of clopidogrel. During this time they received aspirin, heparin, and a $\beta$-blocker, as well as initial treatment with glycoprotein IIb and IIIa inhibitor, but no clopidogrel. Of the 13 operations, 11 were performed without extracorporeal circulation. There were no deaths in this small series. However, there was a statistically significant difference between the two groups with respect to the need for transfusions of packed red blood cells, fresh-frozen plasma, and platelets (Table 1). In addition, 2 of the 6 patients who were operated on while receiving clopidogrel 
TABLE 1. Intraoperative and postoperative transfusions after coronary artery bypass grafting in patients who were receiving clopidogrel or had had clopidogrel discontinued at least 7 days previously

\begin{tabular}{lccc}
\hline & $\begin{array}{c}\text { Group A } \\
\text { (procedure with } \\
\text { clopidogrel) }\end{array}$ & $\begin{array}{c}\text { Group B (clopidogrel } \\
\text { stopped } \geq 7 \text { d before } \\
\text { procedure) }\end{array}$ & $\begin{array}{c}\boldsymbol{P} \\
\text { value }\end{array}$ \\
\hline $\begin{array}{c}\text { Transfusions } \\
\begin{array}{c}\text { Packed red blood } \\
\text { cells (units) }\end{array}\end{array}$ & 10.8 & 1.7 & $<.01$ \\
$\begin{array}{c}\text { Fresh-frozen } \\
\text { plasma (units) }\end{array}$ & 7.7 & 1.7 & $<.01$ \\
\begin{tabular}{c} 
Platelets (units) \\
\hline
\end{tabular} & 9.0 & 0.2 & $<.01$ \\
\hline
\end{tabular}

(group A) required reexploration for bleeding within 12 hours after the operation.

\section{Discussion}

Our experience shows that failure to stop clopidogrel at least 7 days before surgery in patients with acute coronary syndrome necessitating urgent surgical revascularization resulted in unacceptable rates of transfusion and reexploration for bleeding, regardless of the surgical technique used (on- or off-pump surgery). Transfusion of blood and blood products exposes patients to transfusion-related complications, and reexploration related to bleeding has been shown to increase hospital stay and to be associated with an increase in mortality. ${ }^{2}$ Bleeding after surgery is usually multifactorial; however, coagulation disorders or platelet abnormalities, either alone or in combination, are the most probable reasons for bleeding in patients receiving aggressive treatment for acute coronary syndrome. The use of aprotinin has significantly reduced rates of reexploration and excessive bleeding, ${ }^{3}$ but nothing is known about hemostatic effects with clopidogrel.
For patients with an acute coronary syndrome necessitating surgical revascularization, the benefits of antiplatelet therapy in reducing mortality and decreasing myocardial ischemia must be carefully weighed against the risk of bleeding. Clopidogrel has an irreversible effect on platelet function for the entire life span of each individual platelet. Thus once the drug has been discontinued, recovery of overall platelet function will be delayed for several days until a significant number of new platelets have been produced and released. In contrast, glycoprotein IIb and IIIa inhibitors, especially tirofiban, have a short half-life that permits emergency operation without an increased risk of bleeding. ${ }^{4}$ We are therefore convinced that routine out-of-hospital administration of clopidogrel should not be recommended for all patients with acute coronary syndrome. Risk stratification and balancing the therapeutic possibilities for individual patients at any time and place is mandatory for optimizing therapy. Clopidogrel should be given only to those patients who do not need or are not eligible for urgent surgery. For patients receiving clopidogrel, discontinuation of this drug and postponing surgery if possible can reduce postoperative bleeding.

\section{References}

1. Yusuf S, Zhao F, Mehta SR, Chrolavicius S, Tognoni G, Fox KK. Clopidogrel in Unstable Angina to Prevent Recurrent Events trial investigators. Effects of clopidogrel in addition to aspirin in patients with acute coronary syndromes without ST-segment elevation. $N$ Engl J Med. 2001;345:494-502.

2. Dacey LJ, Munoz JJ, Baribeau YR, Johnson ER, Lahey SJ, Leavitt BJ, et al. Reexploration for hemorrhage following coronary artery bypass grafting: incidence and risk factors. Northern New England Cardiovascular Disease Study Group. Arch Surg. 1998;133:442-7.

3. Lemmer JH Jr, Dilling EW, Morton JR, Rich JB, Robicsek F, Bricker DL, et al. Aprotinin for primary coronary artery bypass grafting: a multicenter trial of three dose regimens. Ann Thorac Surg. 1996;62:1659-67.

4. Genoni M, Zeller D, Bertel O, Maloigne M, Turina M. Tirofiban therapy does not increase the risk of hemorrhage after emergency coronary surgery. J Thorac Cardiovasc Surg. 2001;122:630-2. 